\title{
Modulation of the Effector Function of Human Monocytes for Mycobacterium avium by Human Immunodeficiency Virus-1 Envelope Glycoprotein gp120
}

H. Shiratsuchi, J. L. Johnson, Z. Toossi, and J. J. Ellner

Department of Medicine, Case Western Reserve University, University Hospitals, and Cleveland Veterans Administration Medical Center, Cleveland, Ohio 44106

\begin{abstract}
Disseminated Mycobacterium avium infection in AIDS is associated with high tissue burdens $\left(1^{9}-10^{10}\right.$ mycobacteria $/ g$ tissue) of organism. The basis for the extraordinary susceptibility of AIDS to M. avium infection is unclear. HIV or its constituents may alter mononuclear phagocyte functions resulting in enhanced intracellular $M$. avium growth. The effects of an envelope glycoprotein (gp120), a transmembrane protein (p121), and core proteins of HIV-1 on M. avium infection of human monocytes were examined. Preculturing monocytes with gp1 20 inhibited $M$. avium phagocytosis and consistently enhanced intracellular growth of six $M$. avium strains. Pretreatment with p121, gag5, or p24 did not inhibit phagocytosis nor enhance intracellular growth of $M$. avium. Incubation of gp120 with soluble CD4 before addition to monocyte cultures or pretreatment of monocytes with OKT4A abrogated gp1 20 effects on $M$. avium phagocytosis and intracellular growth. gp1 20 also augmented cytokine production by infected monocytes. These results suggest that gp120, but not p121 or core proteins, modulate monocyte phagocytosis and enhance intracellular growth of $M$. avium at least in part through monocyte CD4 receptors. Direct effects of HIV-1 products may, therefore, contribute to the diathesis of AIDS to develop disseminated $M$. avium infection and to the extensive replication of the organisms within tissue macrophages. (J. Clin. Invest. 1994. 93:885-891.) Key words: CD4 receptor • phagocytosis • AIDS • mycobacterial diseases $\bullet$ cytokines
\end{abstract}

\section{Introduction}

Mycobacterium avium is an intracellular pathogen that predominantly parasitizes mononuclear phagocytes, and is the most frequent cause of disseminated infection in patients with AIDS $(1,2)$. Disseminated $M$. avium disease usually occurs late in the course of AIDS and is associated with severe immunosuppression. Although only $3-4 \%$ of AIDS patients have disseminated $M$. avium infection as their initial opportunistic infection, 46-56\% of AIDS patients have evidence of disseminated $M$. avium infection at the time of death $(3,4)$. High

Address correspondence to Dr. Hiroe Shiratsuchi, Biomedical Research Building, 10th Floor, West Administration, Case Western Reserve University, 10900 Euclid Avenue, Cleveland, OH 44106-4984.

Received for publication 10 May 1993 and in revised form 5 October 1993.

J. Clin. Invest.

(c) The American Society for Clinical Investigation, Inc.

$0021-9738 / 94 / 02 / 0885 / 07 \quad \$ 2.00$

Volume 93, February 1994, 885-891 tissue burdens of $M$. avium ( $10^{9}-10^{10}$ acid-fast bacilli [AFB $]^{1} /$ $\mathrm{g}$ tissue) have been documented in AIDS patients (5). The pathophysiologic mechanisms underlying the extraordinary intracellular growth of this organism are unknown.

Mononuclear phagocytes, including monocytes and tissue macrophages, are important effector cells against mycobacteria and other intracellular pathogens. Unlike CD4 lymphocytes, which are the major reservoir of HIV-1, < $1 \%$ of monocytes and up to $10 \%$ of tissue macrophages obtained from AIDS patients are infected with HIV-1 $(6,7)$, implying that factors other than direct infection with HIV-1 are involved in the exuberant intracellular growth of $M$. avium in patients with AIDS.

The initial step in HIV infection of T cells and monocytes is mediated by specific binding of the viral envelope protein gp 120 to the CD4 molecule $(8,9)$. Soluble CD4 (sCD4) binds to gp120 and blocks HIV-1 infection of human cells $(10,11)$. In vitro studies of the effects of HIV and its envelope protein, gp120, on macrophage function have generated conflicting results. Infection with HIV- 1 in vitro enhances IL- 1 and TNF- $\alpha$ expression by human monocytic cell lines stimulated with LPS $(12,13)$. In early reports, live and killed HIV induced expression of IL-1, IL-6, and TNF- $\alpha$ by human monocytes (14, 15). Native, but not recombinant, gp1 20 induces cytokine expression by monocytes from healthy subjects (16). In another study, however, mononuclear cells stimulated with HIV or gp120 failed to produce cytokines when effects of LPS were excluded (17). HIV gp120 also inhibited monocyte chemotaxis via downregulation of ligand receptors (18). It is not known whether effector functions of mononuclear phagocytes are affected by HIV-1 gp 120. In this study, we demonstrate that pretreatment of human monocytes with HIV-1 gp120 inhibits phagocytosis and enhances intracellular growth of M. avium.

\section{Methods}

Microorganisms. M. avium strains LR147 and LR114 were kindly donated by J. Crawford (McClellan Veterans Hospital, Little Rock, AK). Strain 10-153 was provided by A. Tsang (National Jewish Hospital, Denver, CO). Strains $86 \mathrm{~m} 2096$ and SV4(4/44) were clinical isolates from AIDS patients at University Hospitals (Cleveland, $\mathrm{OH}$ ). Strain $2151 \mathrm{SmD}$ is an $M$. avium strain with smooth, domed colonial morphology cloned from an isolate donated by I. Orme (Colorado State University, Fort Collins, CO). M. avium were grown in Middlebrook $7 \mathrm{H} 9$ broth at $37^{\circ} \mathrm{C}$, aliquoted, and stored at $-70^{\circ} \mathrm{C}$ until use.

Reagents. Recombinant HIV-1 envelope glycoprotein gp120 expressed in baculovirus, core protein gag5 (an HIV-1 core protein containing 182 amino acids from the core protein p24), transmembrane

1. Abbreviations used in this paper: AFB, acid-fast bacilli; GI, growth index; sCD4, soluble CD4. 
envelope protein p121 (an HIV component peptide containing 82 amino acids from the immunodominant region of envelope protein gp41) expressed in Escherichia coli, and recombinant sCD4 were obtained from RepliGen (Boston, MA). Recombinant gp120 and core protein p24 expressed in a baculovirus system were obtained from American Bio-Technologies, Inc. (Cambridge, MA). OKT4 and OKT4A monoclonal antibodies were obtained from Orthodiagnostics System Inc. (Raritan, NJ) and dialyzed before use. Endotoxin contamination of all reagents was $<0.2 \mathrm{ng} / \mu \mathrm{g}$ of protein by limulus amebocyte lysate assay.

Monocyte separation and culture. PBMC were isolated from heparinized venous blood obtained from HIV-negative healthy subjects and suspended in RPMI 1640 (M. A. Whittaker Bioproducts, Walkersville, MD) supplemented with $5 \%$ autologous unheated serum (complete medium). Three 50- $\mu$ l PBMC $\left(10^{7} / \mathrm{ml}\right)$ suspensions were placed in $35-\mathrm{mm}$ petri dishes and incubated for $60 \mathrm{~min}$ at $37^{\circ} \mathrm{C}$. Nonadherent cells were removed by washing the plates two times with prewarmed medium. The monocytes were precultured with or without recombinant HIV-1 protein for $2 \mathrm{~d}$ in complete medium at $37^{\circ} \mathrm{C}, 5 \% \mathrm{CO}_{2}$ in air and then infected with $1.5 \mathrm{ml}$ of $M$. avium suspension $\left(10^{7}\right.$ bacteria $/ \mathrm{ml}$ in complete medium) for $60 \mathrm{~min}$ at $37^{\circ} \mathrm{C}$. The dishes were washed four times with prewarmed medium to remove extracellular bacteria and were cultured in $2 \mathrm{ml}$ of complete medium for $7 \mathrm{~d}$. Representative plates were fixed with methanol for assessment of phagocytosis. Samples were harvested at time 0 (immediately after infection) and $7 \mathrm{~d}$ after infection for CFU assay. The density of monocyte monolayers as assessed by counting cell nuclei with naphthol blue black staining (19) was comparable between control and gp120-pretreated cultures throughout the 7-d culture period.

Most $M$. avium growth using this experimental system is intracellular and not due to adherence (19). We (unpublished data) and Schnittman et al. (20) also have confirmed by electron microscopy that $M$. avium growth occurs predominantly within monocytes in this in vitro infection system.

Blocking of gp120 effect by sCD4 or OKT4A antibody. To neutralize gp120, gp120 $(1 \mu \mathrm{g})$ was incubated with sCD4 $(1 \mu \mathrm{g})$ at room temperature for $30 \mathrm{~min}$ before addition to monocyte cultures. Monocytes were precultured with medium alone, gp120 $(0.2 \mu \mathrm{g} / \mathrm{ml}), \mathrm{sCD} 4$ $(0.2 \mu \mathrm{g} / \mathrm{ml})$, or gpl 20 preincubated with $\mathrm{sCD} 4$ (final concentration, $0.2 \mu \mathrm{g} / \mathrm{ml}$ each) for $2 \mathrm{~d}$ before infection.

Monocytes were incubated with OKT4 or OKT4A monoclonal antibodies ( $1: 200$ dilution) for $60 \mathrm{~min}$ at $37^{\circ} \mathrm{C}$ before pretreatment with gp120. Monocytes preincubated with OKT4 or OKT4A and untreated monocytes were precultured with gp1 $200.2 \mu \mathrm{g} / \mathrm{ml}$ for $2 \mathrm{~d}$ before infection with $M$. avium.

Counting of $A F B$. Immediately after infection with $M$. avium, petri dishes were fixed with methanol and stained by Kinyoun's modified acid-fast method. The number of intracellular mycobacteria was determined by counting AFB within monocytes by oil immersion light microscopy at $\times 1,000$. The percentage of monocytes infected with $\geq 1$ AFB and the total number of AFB per 100 monocytes were calculated as described previously $(19,21)$ and the data reported as mean \pm SEM.

Counting of CFU. The number of $M$. avium in each sample was assessed by CFU assay as described previously $(19,21)$. Monocytes were lysed by adding $1.1 \mathrm{ml}$ of Middlebrook $7 \mathrm{H} 9$ medium and $0.4 \mathrm{ml}$ of $0.25 \%$ SDS in PBS to each petri plate for $10 \mathrm{~min}$. Monocyte lysates were then transferred to tubes containing $0.5 \mathrm{ml}$ of $20 \%$ BSA to neutralize the SDS, sonicated for $20 \mathrm{~s}$ to assure a single-cell suspension of mycobacteria, and serially 10 -fold diluted in $7 \mathrm{H} 9$ medium. 10- $\mu$ l aliquots of each dilution were plated in triplicate on Middlebrook 7H10 agar supplemented with oleic acid-albumin-dextrose-catalase (Difco Laboratories, Detroit, MI). The agar plates then were incubated at $37^{\circ} \mathrm{C}$ for 4-7 d until visible colonies were present. The number of colonies at each dilution was counted using a stereomicroscope and averaged. Data were expressed as an intracellular $M$. avium growth index (GI) calculated as CFU in day 7 monocyte lysate divided by CFU in day 0 monocyte lysate.

Cytokine generation and assay. Monocyte monolayers were precultured with or without gp $120(1 \mu \mathrm{g} / \mathrm{ml})$ for $2 \mathrm{~d}$ and then stimulated with
M. avium for another $24 \mathrm{~h}$ in complete medium. Culture supernatants were harvested, filtered through $0.2-\mu \mathrm{m}$ filters to remove cell debris, and stored at $-70^{\circ} \mathrm{C}$ until assay. Immunologically reactive cytokines (IL-1, IL-6, and TNF- $\alpha$ ) contained in samples were assayed by the ELISA method using commercially available kits ( R \& D Systems, Minneapolis, MN).

Expression of cytokine mRNA. Adherent monocytes were precultured in a $60-\mathrm{mm}$ petri dish ( 1007 ; Falcon Labware, Oxnard, CA ) with or without $\mathrm{gp} 120(1 \mu \mathrm{g} / \mathrm{ml})$ for $2 \mathrm{~d}$ and then infected with $M$. avium. Monocytes were cultured for $24 \mathrm{~h}$. Total RNA was extracted by the guanidinium cesium method (22). RNA was electrophoretically separated on a $1 \%$ agarose- $2 \mathrm{M}$ formaldehyde gel, and transferred to nylon membranes (GIBCO BRL, Gaithersburg, MD). RNA then was crosslinked to the membrane using UV light (Stratagene, La Jolla, CA). Prehybridization was done at $42^{\circ} \mathrm{C}$ in a solution containing $50 \%$ formamide, $5 \times$ Denhardts' solution $(100 \times=2 \%$ Ficoll, $2 \%$ polyvinylpyrrolidone, $2 \%$ bovine serum albumin ), $5 \times$ SSC, and $0.5 \%$ SDS, with heat denatured salmon sperm DNA $(100 \mu \mathrm{g} / \mathrm{ml})$. Hybridization was performed in the same solution to which dextran sulfate (15\% final concentration) was added and contained a ${ }^{32} \mathrm{P}$-labeled $\mathrm{cDNA}$ probe for human IL-1 $\alpha$, IL-6, or TNF- $\alpha$ (provided by Dr. P. Lomedico, Hoffman-La Roche, Inc., Nutley, NJ). Membranes were washed with $2 \times$ SSC and $1 \%$ SDS at $60^{\circ} \mathrm{C}$ for $1 \mathrm{~h}$ with agitation, and exposed to XAR-5 film (Kodak Laboratories, Rochester, NY) at $-70^{\circ} \mathrm{C}$ with an intensifying screen.

Statistical analysis. The significance of differences between cultures with or without HIV-1 protein was calculated by the paired Student's $t$ test.

\section{Results}

Effect of gp120 on monocyte phagocytosis of M. avium. To investigate whether HIV-1 envelope protein gp120 altered monocyte effector functions against $M$. avium, monocytes obtained from healthy HIV-negative subjects were precultured with recombinant HIV-1 gp120 (0-1.0 $\mu \mathrm{g} / \mathrm{ml}$, final concentration) for $2 \mathrm{~d}$ and then infected with virulent $M$. avium strain LR114SmT. The efficiency of phagocytosis of $M$. avium by monocytes was assessed by enumerating intracellular AFB by light microscopy. Maximal effects of gp120 in decreasing phagocytosis of $M$. avium were observed at a concentration of $0.2 \mu \mathrm{g} / \mathrm{ml}$ (data not shown). Pretreatment of monocytes with gp120 $(0.2 \mu \mathrm{g} / \mathrm{ml})$ significantly inhibited phagocytosis of $M$. avium by human monocytes $(P<0.001)$ (Table I). To assess whether these effects on $M$. avium phagocytosis were unique for gp 120, we tested additional HIV structural proteins, gag5 and p121. Monocytes were pretreated with various doses (ranging from 0.05 to $1.0 \mu \mathrm{g} / \mathrm{ml}$ ) of recombinant gag5 or recombinant $\mathrm{p} 121$ for $2 \mathrm{~d}$ and then infected with $M$. avium strain LR114SmT. Pretreatment with gag5 or p121 did not alter monocyte phagocytosis ( Table I). To evaluate whether the observed effects of gp1 20 on $M$. avium phagocytosis were due to residual contaminants derived from the baculovirus expression system, we compared the effects of gp 120 and HIV core protein p24, both expressed in an identical baculovirus system, on $M$. avium phagocytosis. Two preparations of recombinant gp120 (Repligen, Boston, MA; and American Bio-Technologies, Cambridge, MA) had comparable effects in decreasing monocyte phagocytosis of $M$. avium. Phagocytosis of $M$. avium after pretreatment with p24 also expressed in a baculovirus vector system was, however, comparable to control cultures (Table II). These data suggest that the effects of gp1 20 observed were not due to contaminants from the expression vector. 
Table I. Effect of HIV-I Proteins on Phagocytosis of M. avium by Human Monocytes

\begin{tabular}{lccc}
\hline & $n$ & Monocytes infected & AFB/100 monocytes \\
\hline & & $\%$ & \\
Control & 7 & $40.0 \pm 2.5$ & $138 \pm 17$ \\
gp120 & 7 & $28.8 \pm 3.8^{*}$ & $97 \pm 19^{*}$ \\
Control & 3 & $41.5 \pm 7.6$ & $137 \pm 34$ \\
gag5 & 3 & $39.9 \pm 7.8$ & $133 \pm 31$ \\
Control & 4 & $35.7 \pm 4.5$ & $114 \pm 19$ \\
p121 & 4 & $35.0 \pm 4.3$ & $122 \pm 23$ \\
\hline
\end{tabular}

Monocytes obtained from healthy subjects were precultured with or without recombinant HIV-1 gp120 $(0.2 \mu \mathrm{g} / \mathrm{ml})$, gag $5(0.2 \mu \mathrm{g} / \mathrm{ml})$, or p121 $(0.2 \mu \mathrm{g} / \mathrm{ml})$ for $2 \mathrm{~d}$ before infection. Data are expressed as the mean \pm SE of the percent monocytes infected with $\geq 1$ AFB or the number of AFB per 100 monocytes. ${ }^{*} P<0.001$ compared with control (paired $t$ test).

Effect of gp120 on intracellular growth of M. avium in human monocytes. Intracellular growth of $M$. avium in human monocytes was assayed by detection of viable mycobacteria in monocyte lysates using a CFU assay $(19,21)$. Pretreatment of human monocytes with $0.2 \mu \mathrm{g} / \mathrm{ml} \mathrm{gp} 120$ maximally enhanced intracellular growth of $M$. avium (Fig. 1). Since $M$. avium strains differ markedly in their capacity for intracellular growth in human monocytes, the effect of gp120 on intracellular growth of multiple strains of $M$. avium also was examined. Pretreatment of monocytes with gp120 $(0.2 \mu \mathrm{g} / \mathrm{ml})$ consistently increased intracellular $M$. avium growth using six strains of $M$. avium, including two avirulent (SV4[4/44] and 2151SmD) and four virulent strains (LR114SmT, LR 147, 10135 , and $86 \mathrm{~m} 2096)$ (Table III). Pretreatment with gag5 $(0.2$ $\mu \mathrm{g} / \mathrm{ml}$ ) did not enhance intracellular growth of $M$. avium (19.9 \pm 10.4 [control] vs. $17.6 \pm 8.9$ [gag5] GI). Thus, in contrast to HIV-1 envelope protein gp120, HIV-1 core protein gag5 and the transmembrane portion of HIV-1 envelope protein p121 neither affected mycobacterial phagocytic efficiency nor enhanced the intracellular growth of $M$. avium.

Blocking of gp120 effects by SCD4 and OKT4A antibody. HIV-1 gp 120 binds specifically to CD4 receptors on helper T lymphocytes. Incubation with $\mathrm{sCD} 4$ or OKT4A monoclonal

Table II. Effect of Recombinant HIV-derived Proteins from a Baculovirus Expression System on M. avium Phagocytosis

\begin{tabular}{lccc}
\hline & Source & Monocytes infected & AFB/100 monocytes \\
\hline & & $\%$ & \\
Control & - & $13.2 \pm 1.9$ & $40.2 \pm 7.7$ \\
gp120 & RepliGen & $4.5 \pm 1.0^{*}$ & $10.9 \pm 2.9$ \\
gp120 & ABT & $6.0 \pm 0.9^{*}$ & $19.6 \pm 5.1$ \\
p24 & ABT & $12.7 \pm 0.2$ & $41.5 \pm 3.3$ \\
\hline
\end{tabular}

Monocytes from three healthy subjects were precultured with recombinant HIV proteins $(0.2 \mu \mathrm{g} / \mathrm{ml})$ for $2 \mathrm{~d}$ before infection. All recombinant proteins were produced using a baculovirus expression vector. Data are expressed as mean $\pm \mathrm{SE}$ of the percent monocytes infected with $\geq 1$ AFB or the number of AFB per 100 monocytes. ${ }^{*} P<0.05$ compared with control (paired $t$ test). ${ }^{\ddagger}$ American Bio-Technologies, Inc.

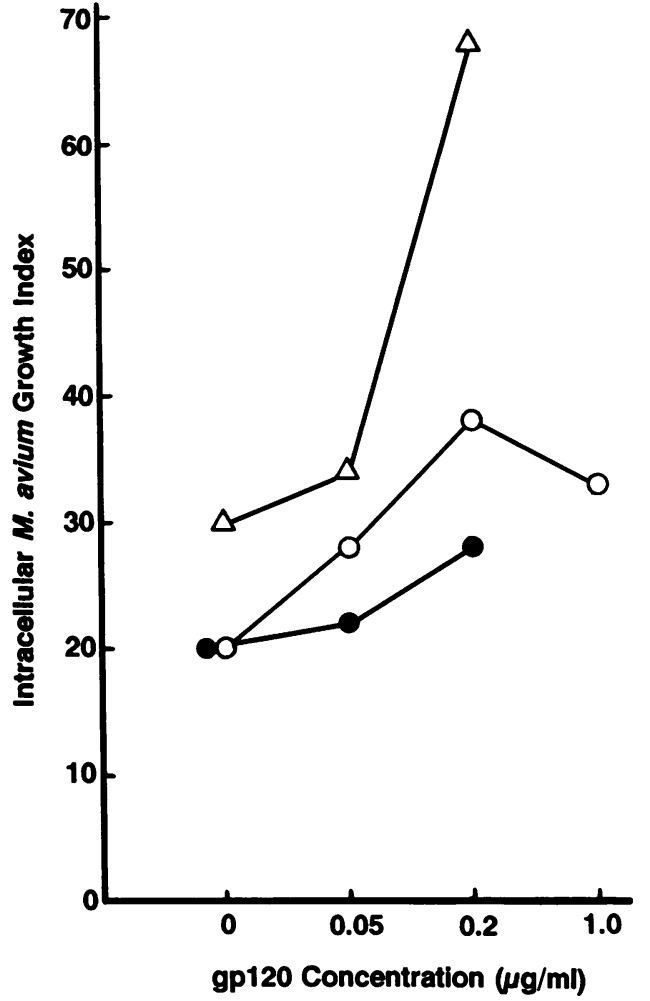

Figure 1. Effect of gp1 20 on intracellular growth of virulent $M$. avium strain LR114SmT in human monocytes. Monocytes obtained from healthy HIV-negative donors were precultured with or without gp 120 (at doses ranging from 0 to $1.0 \mu \mathrm{g} / \mathrm{ml}$, final concentration) for $2 \mathrm{~d}$ before infection. After infection with $M$. avium strain LR114SmT, monocytes were cultured with medium alone for $7 \mathrm{~d}$. Data are expressed as an intracellular $M$. avium growth index (GI). Data shown are from three separate experiments.

antibody blocks gp 120 binding to CD4 and abrogates HIV infection of CD4-positive lymphocytes $(10,11)$. Human monocytes also possess CD4 receptors (23) and binding of gp 120 to human monocytes has been demonstrated; however, binding was blocked only $28 \%$ by sCD4 (24). To examine whether the effects of gp120 on monocyte phagocytosis and intracellular

Table III. Effect of HIV-1 gp120 on Intracellular Growth of Various Strains of $M$. avium

\begin{tabular}{lllc}
\hline & & \multicolumn{2}{c}{ GI } \\
\cline { 3 - 4 } M. avium strain & $n$ & Control & gp120 \\
\hline SV4 (4/44) & 3 & $1.51 \pm 0.14$ & $3.00 \pm 0.33$ \\
2151 SmD & 3 & $1.74 \pm 1.02$ & $2.67 \pm 1.25$ \\
LR114 SmT & 6 & $30.5 \pm 7.5$ & $53.8 \pm 8.9^{*}$ \\
LR147 & 3 & $23.4 \pm 17.0$ & $43.0 \pm 32.2$ \\
10-153 & 3 & $54.9 \pm 43.1$ & $76.8 \pm 46.1^{*}$ \\
$86 \mathrm{~m} 2096$ & 3 & $66.9 \pm 34.4$ & $126.9 \pm 55.8$
\end{tabular}

Monocytes obtained from three healthy HIV-negative donors were precultured with or without $0.2 \mu \mathrm{g} / \mathrm{ml} \mathrm{gp} 120$ for $2 \mathrm{~d}$ and then infected with two avirulent and four virulent $M$. avium strains. The number of viable $M$. avium in monocyte lysates of each sample was assessed by CFU assay. Data are expressed as mean $\pm \mathrm{SE}$ of a GI. ${ }^{*} P<0.05$ compared with control (paired $t$ test). 
growth of $M$. avium were mediated via CD4 molecules on monocytes, blocking experiments with recombinant sCD4 and monoclonal OKT4A antibody were performed. Monocytes from healthy subjects were precultured for $2 \mathrm{~d}$ with medium alone, gp120, OKT4, OKT4A, sCD4, or gp120 reacted to sCD4, and then infected with $M$. avium strain LR114SmT. In additional experiments, monocytes were preincubated in the presence or absence of monoclonal antibody OKT4 or OKT4A for $60 \mathrm{~min}$ at $37^{\circ} \mathrm{C}$ before treatment with gp120. Phagocytosis of $M$. avium was assessed by counting the number of AFB ingested by monocytes. gp 120 significantly inhibited $M$. avium phagocytosis. Both preincubation of gp 120 with sCD4 before addition to monocyte cultures and pretreatment of monocytes with OKT4A antibody before incubation with gp120 blocked the effect of gp120 on M. avium phagocytosis (Fig. 2). Monocyte pretreatment with OKT4 before incubation with gp120 also failed to abrogate the effect of gp120 in inhibiting $M$. avium phagocytosis (Table IV). Pretreatment of monocytes with OKT4 or OKT4A alone had no effect on $M$. avium phagocytosis. Preincubation of gp 120 with sCD4 also neutralized the ability of gp120 to enhance intracellular growth of $M$. avium (Table V). sCD4, OKT4, or OKT4A alone had no effect on

$\mathbf{A}$

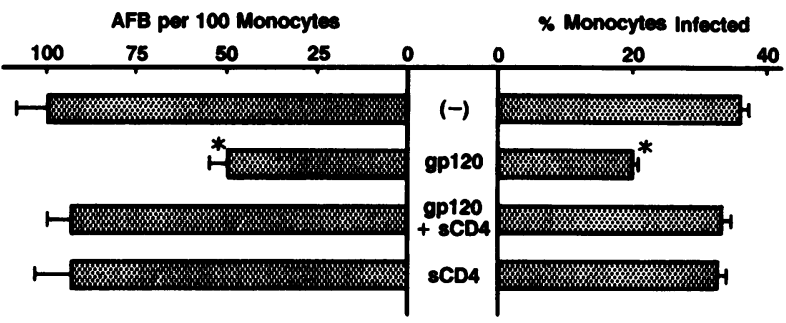

$\mathbf{B}$

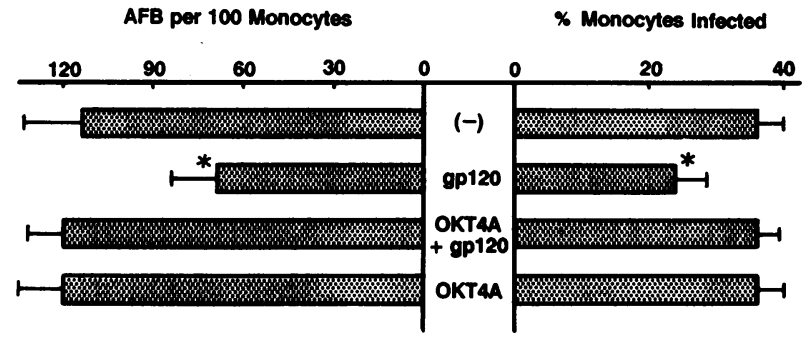

Figure 2. Neutralization of the effects of gp 120 on monocyte phagocytosis of $M$. avium by sCD4 or monoclonal OKT4A antibody. Phagocytosis of $M$. avium was assayed by counting AFB. $(A)$ gp 120 $(0.2 \mu \mathrm{g} / \mathrm{ml})$ was preincubated with recombinant sCD4 $(0.2 \mu \mathrm{g} / \mathrm{ml})$ at room temperature for $30 \mathrm{~min}$ before addition to monocyte cultures. Monocytes from three healthy subjects were cultured with me-

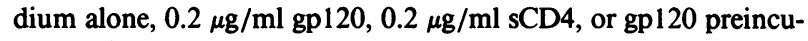
bated with SCD4 for $2 \mathrm{~d}$ and then infected with $M$. avium strain LR114SmT. Data are shown as the mean \pm SE monocytes ingesting $\geq 1 \mathrm{AFB}$ or the number of AFB per 100 monocytes in 3 independent experiments using monocytes from healthy subjects. ${ }^{*} P<0.02$ compared with control culture, or $\mathrm{sCD} 4+\mathrm{gp} 120$, or sCD4 alone; paired $t$ test. ( $B$ ) Monocytes obtained from four healthy subjects were preincubated with monoclonal antibody OKT4A (1:200 dilution) at $37^{\circ} \mathrm{C}$ for $60 \mathrm{~min}$ before addition of gp 120 to monocyte culture. OKT4A-pretreated or untreated monocytes were cultured with or without $0.2 \mu \mathrm{g} / \mathrm{ml} \mathrm{gp} 120$ for $2 \mathrm{~d}$ and then infected with $M$. avium strain LR114SmT. Data are shown as mean \pm SE of monocytes ingesting $\geq 1$ AFB or the number of AFB per 100 monocytes in 4 independent experiments using monocytes from healthy subjects. ${ }^{*} P$ $<0.01$ compared with control culture or OKT4A + gp 120 or OKT4A alone; paired $t$ test.
Table IV. Effects of OKT4 and gp120 on M. avium phagocytosis

\begin{tabular}{|c|c|c|}
\hline & \multicolumn{2}{|c|}{ Monocytes infected } \\
\hline & Exp. 1 & Exp. 2 \\
\hline & \multicolumn{2}{|c|}{$\%$} \\
\hline - & 59.5 & 37.7 \\
\hline gp120 & 41.5 & 23.1 \\
\hline OKT4 & 58.0 & 44.3 \\
\hline OKT4 + gp120 & 43.4 & 29.8 \\
\hline
\end{tabular}

Monocytes from heatlhy subjects were incubated with OKT4 for 60 min before coculture with gp1 20 for $2 \mathrm{~d}$. Monocytes were infected with $M$. avium. Data are expressed as the percentage of monocytes ingesting $\geq 1$ AFB.

intracellular growth of $M$. avium. These data suggest that the capacity of HIV gp120 to inhibit phagocytosis and enhance intracellular growth of $M$. avium was mediated via interactions with CD4 receptors on human monocytes.

Effect of gp120 on cytokine induction by monocytes infected with $M$. avium. Previously, we demonstrated that $M$. avium infection induced cytokine production by monocytes and that certain cytokines such as IL-1 and IL-6 augmented $M$. avium replication $(25,26)$. The balance between cytokines that increase mycobacterial growth and those that augment intracellular killing may be important in determining effector function against $M$. avium infection. Several studies have demonstrated monocyte activation by HIV-1 gp1 20 to express cytokines (14, 16). To examine whether gp120 modulated cytokine expression when monocytes were exposed to gp120 before infection with $M$. avium, monocyte monolayers were precultured with or without gp120 $(0.2-1.0 \mu \mathrm{g} / \mathrm{ml})$ for $2 \mathrm{~d}$ and then infected with $M$. avium strain LR1 14SmT. Cytokine production in culture supernatants (Table VI) and cytokine-specific mRNA expression (Fig. 3) were assessed. As shown in Table VI, pretreatment with gp 120 induced only minimal IL-1, TNF- $\alpha$, and IL-6 production. Infection of human monocytes with $M$. avium augmented cytokine production. A synergistic effect of gp120 on $M$. avium-induced cytokine expression by monocytes was evident; monocytes precultured with gp120 and then stimulated with $M$. avium expressed a significantly higher concentration of immunoreactive II -1 , TNF- $\alpha$, and IL- 6 than mono-

Table V. Neutralization by sCD4 of gp120 Effects on Intracellular M. avium Growth

\begin{tabular}{lcc}
\hline & \multicolumn{2}{c}{ GI } \\
\cline { 2 - 3 } & Exp. 1 & Exp. 2 \\
\hline- & 2.8 & 35.4 \\
gp120 & 7.8 & 45.8 \\
sCD4 & 3.4 & 36.4 \\
gp120+ sCD4 & 4.0 & 35.0 \\
\hline
\end{tabular}

Monocytes were precultured with or without gp 120, sCD4, or a combination of gp 120 and SCD4 for $2 \mathrm{~d}$ before infection with $M$. avium strain LR114F. gp1 20 was preincubated with sCD4 for $30 \mathrm{~min}$ at room temperature before addition to monocyte cultures. Data are expressed as GI (day $7 \mathrm{CFU} /$ day $0 \mathrm{CFU}$ ). 
Table VI. Effect of gp120 on Induction of Cytokine Expression by Human Monocytes

\begin{tabular}{lcccc}
\hline & IL-1 $\alpha$ & IL-1 $\beta$ & TNF- $\alpha$ & IL-6 \\
\hline & $p g / m l$ & $p g / m l$ & $p g / m l$ & $n g / m l$ \\
- & $3 \pm 1$ & $221 \pm 60$ & $112 \pm 85$ & $2.1 \pm 0.9$ \\
gp120 & $17 \pm 8$ & $398 \pm 124$ & $159 \pm 69$ & $4.4 \pm 2.7$ \\
$\begin{array}{l}\text { M. avium } \\
\text { gp120 }+\end{array}$ & $23 \pm 4$ & $553 \pm 147$ & $1,708 \pm 624$ & $40.7 \pm 9.4$ \\
$\quad$ M. avium & $81 \pm 22^{*}$ & $1,634 \pm 397^{*}$ & $3,535 \pm 886^{\ddagger}$ & $63.2 \pm 11.6^{\ddagger}$
\end{tabular}

Monocytes from healthy subjects were precultured with or without $\mathrm{gp} 120(1 \mu \mathrm{g} / \mathrm{ml})$ for $2 \mathrm{~d}$ and then stimulated with $M$. avium strain LR114 SmT for another $24 \mathrm{~h}$. Cytokine activities in culture supernatants were assayed by ELISA. Data presented are the mean $\pm \mathrm{SE}$ of four to five independent experiments, using monocytes obtained from four to five individual subjects. ${ }^{*} P<0.05,{ }^{\ddagger} P<0.01$ compared with cultures stimulated with $M$. avium alone (paired $t$ test).

cytes stimulated with $M$. avium alone ( $P<0.05$ for IL- $1 \alpha$ and $\beta$, and $P<0.01$ for TNF- $\alpha$ and IL-6).

TNF- $\alpha$-, IL-6-, and IL- $1 \alpha$-specific mRNA expression in monocytes pretreated with gp120 and then stimulated with $M$. avium were assayed by Northern blot analysis (Fig. 3). Stimulation of monocytes with $M$. avium induced significant cytokinespecific mRNA expression above baseline. Pretreatment with gp120 followed by $M$. avium stimulation resulted in higher mRNA expression than stimulation with gp120 or $M$. avium alone. These results indicate that gp 120 augments cytokine production by monocytes infected with $M$. avium, a property that may result in increased intracellular growth of the organisms.

\section{Discussion}

The late stages of HIV infection are characterized by repeated, often incurable opportunistic infections in the setting of progressive immunosuppression with declining cell-mediated host immunity and increased HIV replication. Considerable controversy exists regarding whether HIV or specific viral constituents or products directly impair(s) host immune defenses against opportunistic pathogens or whether the increased occurrence of these infections is due to indirect effects of HIV mediated by progressive depletion of the CD4 helper T cell population.

Disseminated $M$. avium disease is common in the late stages of HIV infection. In this study we present evidence that the HIV-1 envelope protein gp1 20 impairs in vitro monocyte effector functions against $M$. avium. We demonstrate that despite inhibition of phagocytosis, HIV envelope protein gp120 enhanced intracellular growth of $M$. avium in human monocytes from healthy subjects. Other HIV-1 proteins, including core and transmembrane proteins, did not affect monocyte functions against $M$. avium. Blocking experiments with sCD4, OKT4A, and OKT4 suggest that the effects of gp120 on decreasing phagocytosis and augmenting intracellular growth of $M$. avium are at least partly mediated via CD4 receptors on human monocytes.

$M$. avium is an intracellular pathogen; its major site of growth in human tissues is within tissue macrophages. Tissue macrophages in AIDS patients with disseminated $M$. avium infection are filled with innumerable mycobacteria. Earlier

studies produced conflicting data regarding whether mononuclear phagocytes of AIDS patients were intrinsically more permissive to intracellular $M$. avium growth. Effector functions of monocytes from patients with AIDS were intact when tested against certain intracellular pathogens $(27,28)$, although cytokine production and $\mathrm{Fc}$ and $\mathrm{C} 3$ receptor-mediated phagocytosis were defective $(29,30)$. We and others demonstrated preserved effector cell function of monocytes obtained from AIDS patients against in vitro $M$. avium infection $(20,21)$. In contrast, Crowle et al. (31) reported that monocyte-derived macrophages of AIDS patients exhibited enhanced intracellular $M$. avium growth.

Direct effects of HIV infection on human monocyte effector functions against $M$. avium have been studied by in vitro HIV infection of monocytes from healthy subjects. Dual infection of human monocyte-derived macrophages with HIV and $M$. avium did not alter intracellular mycobacterial growth in short-term culture (32), but increased permissiveness of HIV1 -infected macrophages for intracellular $M$. avium growth was present after $14 \mathrm{~d}$ of culture (33). In vitro monocyte infection with HIV may not, however, accurately reflect conditions in the tissues of patients with AIDS. HIV infection of monocytes and tissue macrophages in AIDS patients is quantitatively lower than T cells $(6,7)$. Therefore, the effects of HIV-1 infection on mononuclear phagocyte effector functions against $M$. avium are likely to be indirect. Constituents of HIV-1 may increase the pathogenicity of AIDS-associated opportunistic infectious agents by interfering with the host effector mechanisms.

HIV-infected lymphocytes and monocytes release viral proteins such as gp120 into culture media in vitro, and HIV gp1 20 has been detected in serum obtained from AIDS patients in concentrations ranging from 0.001 to $0.1 \mu \mathrm{g} / \mathrm{ml}(34)$. We examined the dose-response activity of gp 120 on both phagocytosis and intracellular growth of $M$. avium; optimal responses occurred at a concentration of $0.2 \mu \mathrm{g} / \mathrm{ml}$, twofold higher than the maximal levels found in serum from patients with AIDS. However, HIV replication and viral burden as assessed by RNA PCR and in situ tissue hybridization studies, respectively, were much greater in lymphoid tissue mononuclear cells than in PBMC at all stages of HIV infection (35); it is likely, there-

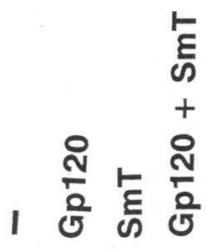

TNF- $\alpha$

$2.0 \mathrm{~kb}$

IL-6

$1.8 \mathrm{~kb}$

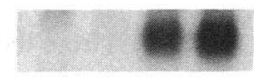

IL-1 $\alpha$

$2.1 \mathrm{~kb}$
Figure 3. Northern blot analysis for cytokine-specific mRNA from monocytes pretreated with $\mathrm{gp} 120$ and stimulated with $M$. avium. RNA was extracted from lysates of monocytes cultured for $24 \mathrm{~h}$ after stimulation with $M$. avium. Each lane was loaded with $5 \mu \mathrm{g}$ of total RNA. 
fore, that tissue levels of gp 120 are substantially higher than those reported in serum, and in the range demonstrated to modulate effector function against $M$. avium.

HIV-1 gp120 specifically binds to CD4 receptors $(8,9)$, and may activate monocytes via this interaction (14). Binding of gp120 to human monocytes has been demonstrated (24). Our data demonstrating that SCD4 and OKT4A, but not OKT4, abrogated the effects of gp 120 indicate that the effects of gp 120 on phagocytosis and intracellular growth of $M$. avium are specifically mediated, at least in part, via CD4 receptors on the monocyte surface. Other HIV-1 proteins, including transmembrane envelope and core proteins, did not show these effects on monocyte effector functions against $M$. avium infection. The effects observed in this study may be specific for gp 120. In a preliminary report, Wagner et al. (36) reported that HIV-1 gp 120 reduced the phagocytosis and enhanced the intracellular growth of Cryptococcus neoformans, another opportunistic pathogen in AIDS patients, by alveolar macrophages. It is not clear whether the effects of gp120 on effector function against $M$. avium and $C$. neoformans are mediated similarly.

Several investigators have shown that gp 120 activates human monocytes to express cytokines $(14,16)$. M. avium infection also induces cytokine production by mononuclear phagocytes such as IL-1, IL-6, IL-10, TNF- $\alpha$, and TGF- $\beta$ (26, 37, 38 ). We have previously reported that certain cytokines such as IL- $\alpha$ and IL-6 enhanced intracellular and extracellular $M$. avium growth $(25)$ and Bermudez and Champsi $(37,38)$ have shown that TGF- $\beta$ and IL-10, immunosuppressive cytokines, enhanced intracellular $M$. avium growth. In this study, pretreatment of human monocytes with gp 120 synergistically augmented production of IL-1, TNF- $\alpha$, and IL- 6 when monocytes were infected with $M$. avium. Induction of these and other cytokines by HIV-1 proteins might modulate the ability of mononuclear phagocytes to limit intracellular growth of this pathogen. Unfavorable alterations in the dynamic local balance of these mycobacterial growth-inhibiting and growth-enhancing factors may lead to increased intracellular replication of this pathogen.

In addition to alterations in cytokine expression, HIV-1 products may impair other aspects of monocyte defenses against intracellular pathogens. Macrophage phagosome-lysosome fusion is another important intermediate step in the killing of intracellular pathogens such as mycobacteria. Estevez et al. (39) have shown that gp120 inhibits macrophage phagosome-lysosome fusion after phagocytosis of opsonized zymosan particles (39), providing another potential basis for its action on intracellular M. avium growth.

In AIDS patients with disseminated $M$. avium infection, therefore, abnormalities in effector functions of mononuclear phagocytes induced by HIV-1 products may contribute to uncontrolled intracellular bacterial growth. Further understanding of the underlying mechanisms of intracellular parasitism by $M$. avium may provide new avenues for therapeutic intervention.

\section{Acknowledgments}

This work was supported by a grant (RO AI-25799) from the National Institutes of Health.

\section{References}

1. Green, J. B., G. S. Sidhu, S. Lewin, J. F. Levine, H. Masur, M. S. Simberkoff, P. Nicholas, R. C. Good, S. B. Zolla-Pazner, A. A. Pollock, M. L. Tapper, and R. S. Holzman. 1982. Mycobacterium avium-intracellulare: a cause of disseminated life-threatening infection in homosexuals and drug abusers. Ann. Intern. Med. 97:539-546.

2. Horsburgh, C. R., Jr. 1991. Mycobacterium avium complex infection in the acquired immunodeficiency syndrome. $N$. Engl. J. Med. 324:1332-1338.

3. Fauci, A. S. 1984. Acquired immunodeficiency syndrome: epidemiologic, clinical, immunologic, and therapeutic considerations. Ann. Intern. Med. 100:92-106.

4. Wallace, J. M., and J. B. Hannah. 1988. Mycobacterium avium complex infection in patients with the acquired immunodeficiency syndrome. A clinicopathologic study. Chest. 93:926-932.

5. Wong, B., F. F. Edwards, T. E. Kiehn, E. Whimbey, H. Donnelly, E. M. Bernard, J. W. M. Gold, and D. Armstrong. 1985. Continuous high-prade $\mathrm{Myco}$ bacterium avium-intracellulare bacteremia in patients with the acquired immunodeficiency syndrome. Am. J. Med. 78:35-40.

6. Schnittman, S. M., M. C. Psallidopoulos, H. C. Lane, L. Thompson, M. Baseler, F. Massari, C. H. Fox, N. P. Salzman, and A. S. Fauci. 1989. The reservoir for HIV-1 in human peripheral blood is a $\mathrm{T}$ cell that maintains expression of CD4. Science (Wash. DC). 245:305-308.

7. Spear, G. T., C. Ou, H. A. Kessler, J. L. Moore, G. Schochetman, and A. L. Landay. 1990. Analysis of lymphocytes, monocytes, and neutrophils from human immunodeficiency virus (HIV)-1 infected persons for HIV DNA. J. Infect. Dis. 162:1239-1244.

8. Klatzmann, D., E. Champagne, S. Chamare, J. Gruest, D. Guetard, T. Hercend, J. Gluckman, and L. Montagnier. 1984. T-lymphocyte T4 molecule behaves as the receptor for human retrovirus LAV. Nature (Lond.). 312:767768.

9. Melendez-Guerrero, M. L., J. K. A. Nicholson, and J. S. McDougal. 1990. In vitro infection of monocytes with $\mathrm{HIV}_{\mathrm{Ba}-\mathrm{L}}$. Effect on cell surface expression of CD4, CD14, HLA-DR, and HLA-DQ. AIDS Res. Hum. Retroviruses. 6:731741.

10. Perno, C. F., M. W. Baseler, S. Broder, and R. Yarchoan. 1990. Infection of monocytes by human immunodeficiency virus type 1 blocked by inhibitors of CD4-gp1 20 binding, even in the presence of enhancing antibodies. J. Exp. Med. 171:1043-56.

11. Deen, K. C., J. S. McDougal, R. Inacker, G. F. Wassermàn, J. Arthos, J. Rosenberg, P. J. Maddon, R. Axe, and R. W. Sweet. 1988. A soluble form of CD4 (T4) protein inhibits AIDS virus infection. Nature (Lond.). 331:82-84.

12. Molina, J., D. T. Scadden, R. Bym, C. A. Dinarello, and J. E. Groopman. 1989. Production of tumor necrosis factor $\alpha$ and interleukin $1 \beta$ by monocytic cells infected with human immunodeficiency virus. J. Clin. Invest. 84:733-737.

13. Yamato, K., Z. El-Hajjaoui, K. Simon, and H. P. Koeffler. 1990. Modulation of interleukin-1 $\beta$ RNA in monocytic cells infected with human immunodeficiency virus-1. J. Clin. Invest. 86:1109-1114.

14. Merrill, J. E., Y. Koyanagi, and I. S. Y. Chen. 1989. Interleukin-1 and tumor necrosis factor $\alpha$ can be induced from mononuclear phagocytes by human immunodeficiency virus type 1 binding to the CD4 receptor. J. Virol. 63:44044408.

15. Nakajima, K., O. Martinez-Maza, T. Hirano, E. C. Breen, P. G. Nishanian, J. F. Salazar-Gonzalez, J. L. Fahey, and T. Kishimoto. 1989. Induction of IL-6 (B cell stimulatory factor-2/IFN- $\beta 2$ ) production by HIV. J. Immunol. 142:531-536.

16. Clouse, K. A., C. M. Cosentino, K. A. Weih, S. W. Pyle, P. B. Robbins, H. D. Hochstein, V. Natarajan, and W. L. Farrar. 1991. The HIV-1 gp1 20 envelope protein has the intrinsic capacity to stimulate monokine secretion. J. Immunol. 147:2892-2901.

17. Molina, J., D. T. Scadden, C. Amirault, A. Woon, E. Vannier, C. A Dinarello, and J. E. Groopman. 1990. Human immunodeficiency virus does not induce interleukin-1, interleukin-6, or tumor necrosis factor in mononuclear cells. J. Virol. 64:2901-2906.

18. Wahl, S. M., J. B. Allen, S. Gartner, J. M. Orenstein, M. Popovic, D. E. Chenoweth, L. O. Arthur, W. L. Farrar, and L. M. Wahl. 1989. HIV-1 and its envelope glycoprotein down-regulate chemotactic ligand receptor and chemotactic function of peripheral blood monocytes. J. Immunol. 142:3553-3559.

19. Shiratsuchi, H., J. L. Johnson, H. Toba, and J. J. Ellner. 1990. Strain- and donor-related differences in the interaction of Mycobacterium avium with human monocytes and its modulation by interferon- $\gamma$. J. Infect. Dis. 162:932-938.

20. Schnittman, S., H. C. Lane, F. G. Witebsky, L. L. Gosey, M. D. Hoggan, and A. S. Fauci. 1988. Host defense against Mycobacterium-avium complex. J. Clin. Immunol. 8:234-43.

21. Johnson, J. L., H. Shiratsuchi, H. Toba, and J. J. Ellner. 1991. Preservation of monocyte effector functions against Mycobacterium avium-M. intracellulare in patients with AIDS. Infect. Immun. 59:3639-3645.

22. Smith, M. F., Jr., F. R. Fuepers, P. R. Young, and J. C. Lee. 1989. A rapid and quantitative method for the determination of interleukin- $1 \alpha$ and $-1 \beta$ mRNA expression in human monocytes and macrophages. J. Immunol. Methods. 118:265-72.

23. Wood, G. S., N. L. Warner, and R. A. Warnke. 1983. Anti-Leu3/T4 antibodies react with cells of the monocyte/macrophage and Langerhans lineage. J. Immunol. 131:212-216.

24. Finbloom, D. S., D. L. Hoover, and M. S. Meltzer. 1991. Binding of 
recombinant HIV coat protein gp120 to human monocytes. J. Immunol. 146:1316-1321

25. Shiratsuchi, H., J. L. Johnson, and J. J. Ellner. 1991. Bidirectional effects of cytokines on the growth of Mycobacterium avium within human monocytes. J. Immunol. 146:3165-3170.

26. Shiratsuchi, H., Z. Toossi, M. A. Mettler, and J. J. Ellner. 1993. Colonial morphotype as a determinant of cytokine expression by human monocytes infected with Mycobacterium avium. J. Immunol. 150:2945-54.

27. Washburn, R. G., C. U. Tuazon, and J. E. Bennett. 1985. Phagocytic and fungicidal activity of monocytes from patients with acquired immunodeficiency syndrome. J. Infect. Dis. 151:565.

28. Murray, H. W., D. Scavuzzo, J. L. Jacobs, M. H. Kaplan, D. M. Libby, J. Schindler, and R. B. Roberts. 1987. In vitro and in vivo activation of human mononuclear phagocytes by interferon- $\gamma$. Studies with normal and AIDS monocytes. J. Immunol. 138:2457-2462.

29. Wright, S. C., A. Jewett, R. Mitsuyasu, and B. Bonavida. 1988. Spontaneous cytotoxicity and tumor necrosis factor production by peripheral blood monocytes from AIDS patients. J. Immunol. 141:99-104.

30. Bender, B. S., B. L. Davidson, R. Kline, C. Brown, and T. C. Quinn. 1988. Role of the mononuclear phagocyte system in the immunopathogenesis of human immunodeficiency virus infection and the acquired immunodeficiency syndrome. Rev. Infect. Dis. 10:1142-54.

31. Crowle, A. J., E. R. Ross, D. L. Cohn, J. Gilden, and M. H. May. 1992. Comparison of the abilities of Mycobacterium avium and Mycobacterium intracellulare to infect and multiply in cultured human macrophages from normal and human immunodeficiency virus-infected subjects. Infect. Immun. 60:3697-703.

32. Meylan, P. R. A., J. R. Munis, D. D. Richman, and R. S. Kornbluth. 1992.
Concurrent human immunodeficiency virus and mycobacterial infection of macrophages in vitro does not reveal any reciprocal effect. J. Infect. Dis. 165:80-86.

33. Källenius, G., T. Koivula, K. J. Rydgård, S. E. Hoffner, A. Valentin, B. Åsjo, C. Ljungh, U. Sharma, and S. B. Svenson. 1992. Human immunodeficiency virus type 1 enhances intracellular growth of Mycobacterium avium in human macrophages. Infect. Immun. 60:2453-58.

34. Oh, S., W. W. Cruikshank, J. Raina, G. C. Blanchard, W. H. Adler, J. Walker, and H. Kornfeld. 1991. Identification of HIV-1 envelope glycoprotein in the serum of AIDS and ARC patients. J. Acquired Immune Defic. Syndr. 5:251256.

35. Pantaleo, G., C. Graziosi, J. F. Demarest, L. Butini, M. Montroni, C. H. Fox, J. M. Orenstein, D. P. Kotler, and A. S. Fauci. 1993. HIV infection is active and progressive in lymphoid tissue during the clinically latent stage of disease. Nature (Lond.). 362:355-358.

36. Wagner, R. P., S. Levitz, J. Bernardo, T. Farrell, and H. Kornfeld. 1990. HIV envelope protein ( $\mathrm{gp} 120$ ) decrease the anti-cryptococcal effect of human bronchoalveolar macrophages. Int. Conf. AIDS. 6:159. (Abstr.)

37. Bermudez, L. E. 1993. Production of transforming growth factor $-\beta$ by Mycobacterium avium-infected human macrophages is associated with unresponsiveness to IFN- $\gamma$. J. Immunol. 150:1838-45.

38. Bermudez, L., and J. Champsi. 1993. Infection with Mycobacterium avium induces production of interleukin-10 (IL-10), and administration of antiIL-10 antibody is associated with enhanced resistance to infection in mice. Infect. Immun. 61:3093-3097.

39. Estevez, M. E., G. Pittis, G. Sternik, and L. Sen. 1992. HIV-1 gp120 inhibits macrophage phagosome-lysosome fusion. Int. Conf. AIDS. 8:A64. (Abstr.) 